\title{
A Qualitative Research on the Difficulties and Failures about Probability Concepts of High School Students
}

\author{
Dilek Sezgin Memnun \\ Department of Elementary Education, Faculty of Education, Uludag University, Turkey \\ E-mail: dsmemnun@uludag.edu.tr
}

Omer Ozbilen (Corresponding author)

Faculty of Engineering, Mersin University, Turkey

E-mail: ozbilen@mersin.edu.tr

Emre Dinc

School of Education, University of Delaware, Newark, United States

E-mail: edinc@udel.edu

Received: December 29, 2018 Accepted: February 17, 2019

Published: February 23, 2019

doi:10.5296/jei.v5i1.14146 URL: https://doi.org/10.5296/jei.v5i1.14146

\begin{abstract}
This research aimed to examine the difficulties and failures of eleventh-grade students regarding probability concepts. With this aim, ten different open-ended probability problems were asked to the 142 eleventh-grade students. Each of these problems requires using different basic probability concepts. It is qualitative research, and the data gathered in this study were analyzed using by descriptive analysis method. The findings indicated that many of these students had difficulties in solving probability problems and failed to apply different probability concepts to these problems. Notably, it was stated that many students had difficulties in finding all the probabilities without any missing in these problems. Besides, it is essential to develop reasoning skills since the students usually used trial-and-error method and prediction to solve probability problems.
\end{abstract}

Keywords: Independent event, Dependent event, Experimental situations, Sample space, Theoretical situations 


\section{Introduction}

\subsection{Introduce the Problem}

Today, with advancements in technology, the need to know different mathematical topics such as problem-solving, statistics, and probability has increased. For this reason, the concept of probability, which has been highlighted among these mathematical subjects, has excited the attention of some international organizations such as NCTM (National Council of Teachers of Mathematics, 2000) and these organizations have started to express the importance of developing an awareness of individuals. In addition, the annual book published by NCTM in 2006 was prepared on the basis of probability and statistics. An important part of the studies conducted in the last quarter of the century investigated probability learning/teaching and examined how students think about probability and how their thoughts have changed (Shaughnessy, 1992). After these developments, many countries recognizing the significance of the subject included probability in mathematics curricula (Munisamy \& Doraisamy, 1998; Papaieronymou, 2010; Tsakiridou \& Vavyla, 2015).

Probability, which has a vital role in both daily and professional life, expresses the possibility of the occurrence of events in numbers. It is a subject of mathematics that enables approaching events from different perspectives. Probability is used especially in decision-making in daily life and the field of humanities (Akdeniz, 2004; Kazak, 2008). When the history related to probability investigated, it has been understood that probability was defined by Pascal and Fermat in 1654, and it has been examined by many researchers from different cultures in different ages. Among these, Laplace had an important role in designating probability as the main concept (Topdemir, 2013). Despite the importance of probability, it is among the most challenging subject for many students at different grade levels (Durmus, 2004; Gurbuz, Toprak, Yapici, \& Dogan, 2011; Kutluca \& Baki, 2009; Tatar, Okur, \& Tuna, 2008). Similarly, it is not easy to develop an understanding of many concepts of probability for many students (Munisamy \& Doraisamy, 1998). Especially in Turkey, probability is one of the subjects that people are having difficulty (Sezgin-Memnun, Altun, \& Yilmaz, 2010). Probability seems to be a simple calculation performed via fractions but requires much effort to be understood (NCTM, 2000). For this reason, it is crucial to examine probabilistic thinking, difficulties or misconceptions related to this subject. Many different studies reveal the difficulties encountered in learning probability concepts. Some of these have been carried out in Turkey (Gurbuz, 2006; Gurbuz, Birgin, \& Catlioglu, 2012; Kazak, 2008; Sezgin-Memnun, Altun, \& Yilmaz, 2010; Tunc, 2006; Unlu \& Aydintan, 2008) and others were carried out in other countries (Bar-On \& Or-Bach, 1988; Batanero \& Serrano, 1999; Fischbein \& Schnarch, 1997; Gage, 2012; Jones, Thornton, Langrall, \& Dogan, 1996; Munisamy \& Doraisamy, 1998; Tsakiridou \& Vavyla, 2015; Way, 1998).

Since probability is rather important both in terms of developing probability-based thinking and reasoning skills and having students acquire the decision-making skills needed in daily life, probability has been included in high school programs since the 1960s and has been emphasized worldwide in different elementary education mathematics programs in the last quarter of the century. Within this scope, probability taught in the eighth grade throughout the 
program changes made since 1990 started to be taught from the fourth grade in the elementary mathematics program published in 2006 in Turkey (Ministry of Education (MEB), 2006). Probability started to be included in elementary education from the early years but was excluded from the tenth-grade mathematics course program, and it has started to be included in the eleventh-grade mathematics course program following the recent revisions (MEB, 2011). Probability subjects, which once included in the tenth-grade mathematics program, began to be taught in the eleventh-grade math lessons in the 2014-2015 educational year. For this reason, it has become essential to reveal students' probabilistic thinking, achievements and difficulties in relation to the subject of probability following the recent modifications in mathematics course programs. Consequently, this study aimed to examine the eleventh-grade students' difficulties and failures in solving probability questions. Having difficulties in understanding the concepts of probability and establishing relations between the information related to the concept of probability (Batanero \& Serrano, 1999; Gurbuz, 2006) reveals the necessity to investigate these issues. It is necessary to determine what kind of problems are encountered in learning the concepts of statistics and probability and what these problems are caused by (Sezgin-Memnun, 2008).

\subsection{Explore Importance of the Problem}

This study is more comprehensive than similar studies because it is expected to give a general idea about students' opinions on the probability concepts included in the mathematics course programs. Moreover, this study will be carried out at the eleventh-grade level, and the researcher did not come across any different studies investigating students' difficulties and failures in solving probability problems in the literature review at this grade level in Turkey since this subject was newly added to the eleventh-grade mathematics course programs. This research is important to indicate eleventh-grade Turkish students' failures in probability and how they use probability concepts. Moreover, in this study, students' difficulties and failures related to probability concepts will be presented in detail by using qualitative research methods. It is thought that this research will contribute to the field with these aspects.

\subsection{Describe Relevant Scholarship}

Bar-On and Or-Bach (1988) reported that the lack of knowledge and skills regarding the subject of sets adversely affected the teaching of probability concept. Batanero and Serrano (1999) conducted a study with the students aged between 14 and 17 years old and found that, although the concept of randomization is a difficult concept to understand, it is necessary for understanding other probability concepts. Gage (2012) indicated that mathematical modeling is important in probability learning. She believes providing real-life problems helps students to develop a broader range of methods and intuitions than the standard approach does. Besides, it could be said that considering multiple representations at the same time and using integers so far as possible help students to get onto the essence of the analysis of a problem. Fischbein and Schnarch (1997) explained that the fifth, seventh, ninth and eleventh grade students intuitively grasped the concepts of probability and that most of these intuitions were inaccurate. Moreover, for different reasons, the researchers reported that students had misconceptions about probability subjects and these misconceptions changed regarding age. 
Jones, Thornton, Langrall, and Dogan (1996) explained that in probability cases it is important that students should determine the number of probability situations in a meaningful way by resorting to part-by-part reasoning, but their insufficient conceptual knowledge about the sample space concept limited their probability learning. Munisamy and Doraisamy (1998) stated that the vast majority of students develop different understandings about probability concepts and have difficulty in finding out about probability events. Tsakiridou and Vavyla (2015) indicated that most of the students were able to recognize various events and categorize them relying upon their likelihood in primary schools. Way (1998) explained that students had difficulty in the questions that should be compared the probabilities of the events due to their lack of knowledge in the fraction and ratio.

Gurbuz (2006) stated that the difficulties in understanding the subject of probability as a result of his work with the eighth-grade students are difficulties in language related to the subject, difficulties in transferring practical applications to mathematical structure, difficulties caused by lack of reasoning, and difficulties arising from the lack of belief in the analyzability of games of chance from certain intuitive perspectives. As a result of the study where Gurbuz, Birgin, and Catlioglu (2012) aimed to compare the students' misconceptions about probability, with the increase in the grade level, they stated that the rate of correct answer was increased, and the misconceptions decreased. Kazak (2008), as a result of his research that examines students' misconceptions about probability, he explained that students used cognitive shortcuts instead of applying known definitions and theories in probability in calculating the probability of an event. Moreover, Sezgin-Memnun, Altun, and Yilmaz, (2010) explained that the level of readiness of eighth-grade students is critical in learning probability concepts. They also reported that students had difficulty in understanding and using the concept of sample space, in making reasoning about probability events, and in interpreting some probability concepts such as discrete event and independent event. In an investigation did with the point of determining the eighth-grade students' achievement levels, Tunc (2006) reported that, within the scope of misconceptions about the use of probability concepts, the students confused independent, dependent and discrete events with one another and could not express the value written above the line in a fraction as it is a subtracted number when finding the probability. In addition, they could not express the concept of the experiment clearly and confused it with the concept of the event, could not determine the sample space, could not explain the difference between a certain event and impossible event, and could not calculate the probability that the event does not occur. Moreover, it was also explained that because students thought that environmental factors and people could be effective in the games of chance and they could not rank the results they achieved correctly, students could not reach the right results. Unlu and Aydintan (2008) declared that the cooperative learning method is more powerful than the traditional teaching method in probability concepts on the academic success.

\subsection{State Hypotheses and Their Correspondence to Research Design}

This research aims to examine the difficulties and report failures of students about probability in the probability problems which require using different basic probability concepts. "What difficulties do the eleventh-grade students have in solving probability problems and what 
failures do they make when solving these problems?"

\section{Method}

This part includes information about the participant students, the data collected with the aim of determining these students' difficulties and failures in solving probability problems, and the statistical analyses.

\subsection{Participants}

A total of 142 volunteer students participated in this research in the fall semester of the 2014-2015 academic year. These students were taking education in the eleventh-grade of three different high schools in a large city in Turkey. In the random sampling method, samples are selected entirely by chance (Yildirim \& Simsek, 2005, p. 104). The participants were selected randomly to be objective and let each participant has an equal chance of participating in the research.

\subsection{Data Collection Tools}

First, a probability test, which was made out of a total of 10 open-ended problems, was formed by considering the eight different acquisitions related to probability included in the mathematics course programs. The problems were related to the daily lives of the students and required for decision-making.

The first problem in the probability test was prepared by benefiting from different resources and course books aimed at revealing whether the students had understood the concepts of sample space, experiment, and output. The second problem aimed to determine if they had understood the concept of probability and the third problem was to figure out if they had grasped the concept of complement. The fourth problem aimed to associate the subject of probability with the subject of sets and the fifth problem aimed to associate it with the subject of equations. The sixth and the seventh problems were prepared with the point of uncovering if the students could make calculations for the discrete, non-discrete, and conditional events. Similarly, the last three problems in the test aimed to reveal if the students could make calculations for dependent and independent events.

Then, the problems in this test were checked by nine different mathematics teachers concerning level, coverage, content, and language. The problems were revised according to the opinions of these teachers.

Before different teachers checked the final revision of this probability test, a pilot study was carried out with a total of 25 eleventh-grade students. Within the extent of this pilot study, the students' answers were classified into categories, and the data reached were assembled under these determined categories. Thus, a preliminary draft evaluation form was prepared to be used in the evaluations. In this way, the comprehensibility and feasibility of the problems in the test were investigated.

\subsection{Data Collection and Analysis}

The probability problems in the study were addressed in written questionnaires, which were sent to the students to solve under the surveillance of their mathematics teachers. It took 
about 50 minutes for the students to answer the problems in the probability test. It was assumed that these eleventh-grade students included their real knowledge and skills in problem solutions.

The students' answers to the probability problems were analyzed using descriptive analysis. The properties of descriptive analysis are; having a systematical and clear description of the data, explaining and interpreting these descriptions, exploring the cause-effect relationships, reaching some concrete findings. Usually, the obtained results are associated and interpreted in terms of themes and predictions are made (Yildirim \& Simsek, 2005, p. 224). In the scope of this study, the data obtained from the answers to the probability problems were presented with a descriptive approach by remaining loyal to their original forms as much as possible and, when necessary, by directly quoting what the participant students said and also adding interpretations about the findings (Walcott, 1994). Within this scope, the obtained data were analyzed by creating a framework, processing the data according to the thematic framework, and describing and interpreting the findings.

At the stage of creating a framework, determining the students' difficulties and failures in solving the probability problems created the most general framework for the data analysis. In the thematic framework stage, the data were arranged under different themes and presented according to this determined framework. At this stage, no answer, incorrect answer, and correct answer formed the three different themes of the study.

At the stage of the description and interpretation of the data, the obtained data were read and arranged according to the determined themes. Later, the arranged data were described, and the findings were interpreted over these themes. In this section, the researcher read and evaluated the data independently. When the research data could not be placed under the themes determined in the pilot study, the discussions were held with a mathematics teacher regarding which answer should be placed under which theme. After that, the rearrangements were made according to the obtained results.

Later, the arranged themes were described, and the reached findings were interpreted through these themes. Then, these data were subjected to specific processes and reduced to numbers: frequency and percentage values were calculated.

Finally, the research findings were supported by direct quotations when necessary.

\subsection{Validity and Reliability}

The validity and reliability of this qualitative study were provided by considering the strategies of conclusiveness, transferability and confirmability strategies (Yildirim \& Simsek, 2005, pp. 264-272).

In this study, conclusiveness and consistency were achieved by conferring to an expert. In this context, the answers were not only evaluated by the researchers but also conferred to a mathematics teacher that leads to increasing the quality of the research. Transferability was achieved by describing and interpreting the typical and changeable characteristics of the study in detail. Confirmability was tried to be achieved by quoting from the data as much as possible and sufficient. Additionally, it has been paid attention to the classification of the research data under the descriptive method, re-arrangement, and interpretation according to 
the determined themes. Moreover, when composing the research findings, attention was paid to their bearing on the characteristics of reasonability, appropriateness for individuals, experiences, conclusiveness, importance, and legibility.

\section{Results}

This section includes the detailed research findings reached as a result of the statistical analyses made with the aim of examining the participant eleventh-grade students' difficulties and failures in solving probability problems and different interpretations made for these findings. First, a total of 142 students' answers to the probability problems were classified, and the percentage and frequency values for this classification are presented in Table 1 below.

Table 1. Percentage and frequency values related to the answers given to the problems

\begin{tabular}{|l|l|l|l|l|l|l|}
\hline \multirow{2}{*}{ Questions } & \multicolumn{3}{l|}{ Correct answer } & \multicolumn{2}{l|}{ Incorrect answer } & \multicolumn{2}{l|}{ No answer } \\
\cline { 2 - 8 } & $\boldsymbol{f}$ & $\boldsymbol{\%}$ & $\boldsymbol{f}$ & $\boldsymbol{\%}$ & $\boldsymbol{f}$ & $\%$ \\
\hline 1 & 21 & 14.8 & 111 & 78.2 & 10 & 7.0 \\
\hline 2 & 79 & 55.6 & 54 & 38.1 & 9 & 6.3 \\
\hline 3 & 8 & 5.6 & 104 & 73.3 & 30 & 21.1 \\
\hline 4 & 43 & 30.2 & 82 & 57.8 & 17 & 12.0 \\
\hline 5 & 50 & 35.2 & 57 & 40.1 & 35 & 24.7 \\
\hline 6 & 50 & 35.2 & 70 & 49.3 & 22 & 15.5 \\
\hline 7 & 87 & 61.3 & 39 & 27.5 & 16 & 11.2 \\
\hline 8 & 117 & 82.4 & 17 & 12.0 & 8 & 5.6 \\
\hline 9 & 71 & 50.0 & 61 & 43.0 & 10 & 7.0 \\
\hline 10 & 40 & 28.2 & 84 & 59.1 & 18 & 12.7 \\
\hline Total & 566 & 39.9 & 679 & 47.8 & 175 & 12.3 \\
\hline
\end{tabular}

From the answers given to the problems in Table 1, it was seen that the students had a total of 679 incorrect answers when solving the probability problems. Moreover, some of the students were unable to respond to some of these problems.

More than half of the students answered correctly the second problem prepared in relation to the concept of probability (55.6\%) and the seventh problem including calculations about conditional probability $(61.3 \%)$. This indicates that the students understood the concepts of probability and conditional probability and can use them in problem-solving. However, the majority of the eleventh-grade students gave incorrect answers to the first problem prepared to reveal if they understood the concepts of sample space, experiment, output, and complement $(78.2 \%)$ and the third problem $(73.3 \%)$. This shows that the eleventh-grade students mostly had difficulty in understanding concepts such as sample space, experiment, 
output, and complement. Also, more than half of the students ( $57.8 \%$ and $59.1 \%$, respectively) gave incorrect answers to the fourth problem, associating the subject of probability with the subject of equations and the tenth problem, requiring the applications of the dependent and independent events. Similarly, nearly half of these students $(49.3 \%$ and $43 \%$, respectively) gave incorrect answers to the sixth problem requiring the applications of discrete and non-discrete events and the ninth problem, covering the applications of the concept of dependent events and the concept of independent events. A great majority of the students $(82.4 \%)$ gave correct answers to the eighth problem, which is about dependent and independent events.

In this part of the study, the students' answers given to each research problem were examined. Firstly, to see if the students understood the concepts of sample space, experiment, and output, the answers given to the first problem were examined and included in the study as: "Find the sample space, experiment and output in the problem of 'Ayşe will choose one skirt and one jacket from among the 2 red skirts, 3 blue skirts, 3 red jackets and one blue jacket in her wardrobe. Find the probability of choosing the same color skirt and jacket"'. In the analyses made, it was observed that a total of 111 participant eleventh-grade students answered this problem incorrectly. For these student answers, the percentage and the frequency values were calculated.

Table 2. Analysis of results related to the incorrect answers given to the first problem

\begin{tabular}{|l|l|l|}
\hline First problem & $\boldsymbol{f}$ & $\%$ \\
\hline Being unable to understand/incorrectly understanding the problem & 71 & 50.0 \\
\hline Incorrectly determining the sample space & 35 & 24.7 \\
\hline Being unable to consider all the conditions & 5 & 3.5 \\
\hline Total & 111 & 78.2 \\
\hline
\end{tabular}

From the incorrect answers giving to the first problem in Table 2, it was found that most of the participants (78.2\%) answered this probability problem incorrectly. When these incorrect answers were examined in detail, it was seen that most of the participants could not reach the right result because they wrote the sample space incorrectly. However, some students could not give correct answers to the problem since they could not consider all the conditions related to the problem or understand the problem. This makes us consider that the participants have difficulties in understanding the concept of sample space, which is one of the basic concepts of probability.

The second problem in the study was prepared with the aim of revealing if the concept of probability was understood and stated as "When a pair of dice are tossed up, what is the probability that the sum of the numbers coming on top surface is smaller than 10?". The answers given by 142 students to this problem were examined, and it was found that 40.1 percent of the participants solved the problem via rhythmic counting. Adversely, some of 
them (14.1\%) found the complementing set and a few students (1.4\%) calculated the probability. However, in the analyses made presented in Table 3, it was understood that a total of 54 participant students answered this problem incorrectly and the percentage and frequency values calculated for these answers.

Table 3. Analysis of results related to the incorrect answers given to the second problem

\begin{tabular}{|l|l|l|}
\hline Second problem & $\boldsymbol{f}$ & $\mathbf{\%}$ \\
\hline Doing rhythmic counting incompletely & 19 & 13.4 \\
\hline Being unable to understand/misunderstanding the problem & 17 & 12.0 \\
\hline Being unable to consider all the conditions & 8 & 5.7 \\
\hline Calculating the probability greater than 1 & 6 & 4.2 \\
\hline Making calculation errors & 2 & 1.4 \\
\hline Writing the sample space incorrectly & 1 & 0.7 \\
\hline Being unable to find/incorrectly finding the complement of a set & 1 & 0.7 \\
\hline Total & 54 & 38.1 \\
\hline
\end{tabular}

It was observed that 38.1 percent of the students answered this problem incorrectly. By examining the incorrect answers in detail, it was understood that some of the students $(25.4 \%$ $=13.4 \%+12 \%$ ) could not reach the result because their rhythmic counting was incomplete, or they were unable to understand the problem. This indicates that a significant number of students (13.4\%) had reasoning incompetence about rhythmic counting. Moreover, some of them $(12 \%)$ could not reach the result because of misunderstanding the problem. Some students could not give correct answers because they were: unable to consider all the conditions related to the problem, calculating the probability as greater than 1, making calculation errors, writing the sample space or the complement of a set incorrectly.

The third research problem in the study was prepared with the aim of revealing whether the concept of complement was understood or not and stated as "Four economists, 3 chemists, 2 engineers will sit around a round table. Find the sitting probability of those who are from the same profession next to one another". The answers given by the participating students to this problem were examined, and it was observed that those who answered this problem correctly did so by doing probability calculations or finding the complement of a set. From the answers of the students who participated in this research in Table 4, it was understood that a total of 104 participant students answered this problem incorrectly and the percentage and the frequency values calculated for these answers. 
Table 4. Analysis of results related to the incorrect answers given to the third problem

\begin{tabular}{|l|l|l|}
\hline Third problem & $\boldsymbol{f}$ & \% \\
\hline Being unable to consider all the conditions & 31 & 21.9 \\
\hline Being unable to understand/misunderstanding the problem & 31 & 21.9 \\
\hline Calculating the probability greater than 1 & 29 & 20.4 \\
\hline Being unable to find/incorrectly finding the complement of a set & 9 & 6.3 \\
\hline Making calculation errors & 4 & 2.8 \\
\hline Total & 104 & 73.3 \\
\hline
\end{tabular}

It was understood in the analyses that a great majority of the eleventh-grade students $(73.3 \%)$ answered this problem incorrectly $(43.8 \%=21.9 \%+21.9 \%)$ because they were unable to consider all the conditions related to the problem or they misunderstood the problem. This indicates that nearly half of the students had reasoning incompetence regarding this problem or difficulty in understanding it. Also, a number of students $(20.4 \%)$ did not know the limits of the probability. Moreover, some students could not give correct answers to the problem because of calculation errors $(6.3 \%)$ and not calculating the complement of a set $(2.8 \%)$.

The eleventh-grade students were given the fourth research problem, which associated the subject of probability with the subject of sets, as: "Of 25 students in a class, 15 prefer mathematics, 12 prefer Turkish, and 6 prefer both mathematics and Turkish. What is the probability that a student randomly selected from the class will be a student not having preferred mathematics or Turkish?" The answers were examined, and it was observed that some of the students $(30.3 \%)$ answered the problem correctly. While a great majority of the students solved the problem by using Venn diagram (23.9\%), some of them (4.9\%) calculated the complement of a set and a few of them (1.4\%) did the probability calculation directly. However, it was observed from Table 5 that a total of 82 students answered this problem incorrectly. The percentage and the frequency values were calculated for student answers.

Table 5. Analysis of results related to the incorrect answers given to the fourth problem

\begin{tabular}{|l|l|l|}
\hline Fourth problem & $\boldsymbol{f}$ & \% \\
\hline Being unable to understand/misunderstanding the problem & 60 & 42.3 \\
\hline Calculating the probability greater than 1 & 11 & 7.8 \\
\hline Making calculation errors & 7 & 4.9 \\
\hline Finding the intersection set incorrectly & 2 & 1.4 \\
\hline Being unable to calculate all the probabilities & 2 & 1.4 \\
\hline Total & 82 & 57.8 \\
\hline
\end{tabular}


In the analysis, it was observed that more than half of the students (57.8\%) answered this probability problem incorrectly. When the incorrect answers related to this problem were examined in detail, it was understood that about half of the students giving incorrect answers to the problem $(42.3 \%)$ could not reach the result because of misunderstanding the probability problem or writing the sample space incorrectly. This indicates that the participants do not understand the probability problem. Some students could not give correct answers to the problem because they calculated the probability as greater than 1, made calculation errors, were unable to give correct reasoning for the intersection set, or were unable to calculate all the probabilities related to the problem. This indicates that the students did not have correct knowledge, especially about the limits of the probability, and they had difficulty in understanding the probability problem.

The fifth problem in the study aimed to determine how the students associated the subject of probability with equations and was stated as: "There are three times more red balls than the black ones in bag $A$ and there are twice as many red balls than the black ones in bag B. What is the probability of drawing balls in different colors when it has been drawn one ball from each bag?" The answers given by the students to this problem were examined, and it was found that most of the participants answered this problem correctly by doing probability calculations. However, it was understood from Table 6 that a total of 57 students answered this problem incorrectly and the percentage and frequency values calculated for these answers.

Table 6. Analysis of results related to the incorrect answers given to the fifth problem

\begin{tabular}{|l|l|l|}
\hline Fifth problem & $\boldsymbol{f}$ & \% \\
\hline Making calculation errors & 19 & 13.4 \\
\hline Being unable to understand/misunderstanding the problem & 18 & 12.7 \\
\hline Being unable to calculate all the probabilities & 11 & 7.5 \\
\hline Calculating the probability greater than 1 & 7 & 4.9 \\
\hline Being unable to consider all the conditions & 2 & 1.4 \\
\hline Total & 57 & 40.1 \\
\hline
\end{tabular}

It was observed in the analyses that 40.1 percent of the students answered this problem incorrectly. When the incorrect answers were examined in detail, some students give incorrect answers to this problem (13.4\%) because of calculation errors, others $(12.7 \%)$ could not understand the problem. This indicates that an important number of students had difficulties making correct calculations and understanding the problem. Moreover, some students could not answer the problem correctly because of being unable to consider all the conditions related to it, by calculating the probability as greater than 1 , or being unable to calculate all the probabilities. 


\section{MInstitute Macrothink $_{\text {Int }}$}

The sixth and the seventh problems in the study were prepared with the aim of determining if the students were able to make calculations for separate, non-separate and conditional events. The sixth probability problem was stated as "When two dice are tossed up, what is the probability that the sum of numbers to come up on the top surface are the multiples of 5 or greater than 9?" and the seventh problem was stated as "In a class of 36 students, there are 12 female and 24 male students, 5 of the female students wear glasses and 12 of the male students wear glasses. Since it is known that any selected student will be the one wearing glasses, what is the probability of that student being a male?"

The answers to the sixth problem were examined, and it was observed that almost all of the students who answered the problem correctly reached the result by doing rhythmic counting and only a few students did a probability calculation. However, when the answers given by students to the seventh problem were examined in Table 7, an important number of the students $(43.7 \%)$ gave correct answers to the problem, and some of them $(16.9 \%)$ reached the correct answer by doing probability calculations. Only one student reached the correct answer by using a Venn diagram. This indicates that the students mostly preferred to draw a table instead of doing probability calculations when reaching the correct answer. However, a total of 70 students (49.3\%) answered the sixth problem, and a total of 39 students $(27.5 \%)$ answered the seventh problem incorrectly.

Table 7. Descriptive analysis of results for incorrect answers in sixth and seventh problems

\begin{tabular}{|l|l|l|}
\hline Sixth problem & $\boldsymbol{f}$ & \% \\
\hline Being unable to consider all the conditions & 28 & 19.7 \\
\hline Being unable to understand/misunderstanding the problem & 28 & 19.7 \\
\hline Making calculation errors & 5 & 3.5 \\
\hline Doing the rhythmic counting incompletely & 5 & 3.5 \\
\hline Being unable to calculate all the probabilities & 4 & 2.9 \\
\hline Total & 70 & 49.3 \\
\hline Seventh problem & $\boldsymbol{f}$ & \% \\
\hline Making calculation errors & 17 & 12.0 \\
\hline Being unable to understand/misunderstanding the problem & 16 & 11.3 \\
\hline Being unable to determine the sample space & 4 & 2.8 \\
\hline Calculating the probability greater than 1 & 2 & 1.4 \\
\hline Total & 39 & 27.5 \\
\hline
\end{tabular}

It was understood in the analyses that nearly half of the students (49.3\%) answered the sixth probability problem incorrectly. An important number of students who answered incorrectly (39.4\%) were unable to reach the right result because they were unable to consider all the 


\section{Macrothink

conditions related to the probability problem (19.7\%) or they misunderstood the problem (19.7\%). This again indicates that nearly half of the students were incapable of reasoning about or understanding the problem. Moreover, some students were unable to give correct answers because of making calculation errors (3.5\%) doing rhythmic counting incompletely $(3.5 \%)$ or being unable to calculate all the probabilities related to the problem $(2.9 \%)$.

An important number of students $(27.5 \%)$ also answered the seventh research problem incorrectly. Some of these $(23.3 \%)$ were unable to reach the result because of being unable to understand the problem $(12 \%)$ or by making calculation errors $(11.3 \%)$. Again, this indicates that some of the students had difficulty performing calculations related to probability and were unable to understand the probability problem. Four students were unable to give correct answers to the problem because of miscalculating the sample space and some students $(1.4 \%)$ calculated the probability value as greater than 1 .

Moreover, in the eighth, ninth and tenth problems, it was aimed to reveal whether the students were able to do calculations related to dependent and independent events. The eighth problem included in the study was a probability problem, stated as: "A proper coin and a proper dice are tossed up. What is the probability of the coin coming up heads and the dice coming up an even number?" The ninth problem was also a probability problem, stated as: "In a bag, there are 2 black and 3 white balls. What is the probability of two randomly drawn balls being in different colours on condition that they will be put back into the bag?" The tenth problem was also a probability problem, stated as: "In a bag, there are 3 green and 5 purple marbles. What is the probability of two of three randomly drawn marbles being green and one being purple, on condition that they will be put back into the bag?" 
Table 8. Results related to the incorrect answers to the eighth, ninth and tenth problems

\begin{tabular}{|l|l|l|}
\hline Eighth problem & $\boldsymbol{f}$ & \% \\
\hline Making calculation errors & 15 & 10.6 \\
\hline Being unable to calculate all the probabilities & 1 & 0.7 \\
\hline Calculating the probability as greater than 1 & 1 & 0.7 \\
\hline Total & 17 & 12.0 \\
\hline Ninth problem & $\boldsymbol{f}$ & $\%$ \\
\hline Being unable to consider all the conditions & 25 & 17.6 \\
\hline Being unable to understand/misunderstanding the problem & 19 & 13.4 \\
\hline Making calculation errors & 11 & 7.8 \\
\hline Calculating the probability as greater than 1 & 5 & 3.5 \\
\hline Being unable to calculate all the probabilities & 1 & 0.7 \\
\hline Total & 61 & 43.0 \\
\hline Tenth problem & $\boldsymbol{f}$ & $\%$ \\
\hline Being unable to consider all the conditions & 44 & 31.0 \\
\hline Being unable to understand/misunderstanding the problem & 35 & 24.6 \\
\hline Making calculation errors & 3 & 2.1 \\
\hline Calculating the probability as greater than 1 & 2 & 1.4 \\
\hline Total & 84 & 59.1 \\
\hline
\end{tabular}

The answers given by the students to these problems were examined, and it was observed that all of the students answered these problems correctly $(82.4 \%, 50 \%$, and $28.2 \%$, respectively) by doing a probability calculation. However, it was revealed in the analyses that a limited number of students $(12 \%)$ answered the eighth probability problem incorrectly, nearly half of them $(43 \%)$ answered the ninth problem incorrectly and more than half of them $(59.1 \%)$ answered the tenth problem incorrectly.

From the incorrect answers giving to these problems in Table 8, it was observed in these detailed analyses that nearly all of the students answering the eighth problem incorrectly $(10.6 \%)$ could not reach the right result because they made calculation errors, and a great majority of the students answering the ninth and the tenth problems incorrectly could not consider all the probabilities in the problems (17.6\% and 31\%) and had difficulty understanding the problem (13.4\% and $24.6 \%$, respectively). This again indicates that the students had insufficient reasoning skills regarding the subject of probability, had difficulty understanding problems and performing probability calculations.

As a result of the evaluations made separately for the answers given to each problem or by each problem group to the problems included within the scope of the study, the students gave incorrect answers to many problems for similar reasons. In order to reveal and understand the 
difficulties and failures experiences about the subject of probability more clearly, the incorrect answers given by the students were prepared in accordance with the acquisitions included in the mathematics course program and are classified.

Table 9. Descriptive analysis of results related to the incorrect answers to the problems

\begin{tabular}{|l|l|l|}
\hline & $\boldsymbol{f}$ & $\boldsymbol{\%}$ \\
\hline Being unable to understand/misunderstanding the problem & 295 & 20.8 \\
\hline Being unable to consider all the conditions & 143 & 10.1 \\
\hline Making calculation errors & 83 & 5.9 \\
\hline Calculating the probability as greater than 1 & 63 & 4.4 \\
\hline Determining the sample space incorrectly & 40 & 2.8 \\
\hline Making the rhythmic counting incompletely & 24 & 1.7 \\
\hline Being unable to calculate all the probabilities & 19 & 1.3 \\
\hline Being unable to find/incorrectly finding the complement of a set & 10 & 0.7 \\
\hline Incorrectly finding the intersection set & 2 & 0.1 \\
\hline Total & 679 & 47.8 \\
\hline
\end{tabular}

From the Table 9, it has been concluded that the students could not solve an important part of the 10 different probability problems $(20.8 \%)$ because they had difficulty in understanding the probability problem and a number of them $(10.1 \%)$ could not solve the problems because they were unable to consider all the conditions related to the problem. This indicates that the students had difficulty in performing the stages of understanding the problem and determining the solution strategies related to the problem put forward by Polya (1985) as the most important stages of solving mathematics problems. However, according to some of the answers given by the students to these problems (5.9\%), that the failures were made because of errors in the probability calculations may indicate that although they had been educated at school, some students had difficulties in subjects, such as fractions and four operations. Similarly, some of the answers given by the students (4.4\%) resulted from not knowing that the probability value is between 0 and 1 . Moreover, some students reached incorrect results because they were unable to: calculate all the probabilities that should be included in their problem solutions, to find the complement of the set, to make complete rhythmic counting and to find the intersection set.

\section{Discussion}

The results displayed that the failures, which the students made in the calculations for some probability problems included in the study (especially for the eighth problem of the study), made us conclude that they had difficulties in fractions, percentage calculations and four arithmetical operations with numbers. This overlaps the results obtained in the studies made 
by Jones et al. (1996), and Sezgin-Memnun, Altun, and Yilmaz (2010) that the students had difficulty, especially in understanding and using the concept of sample space. It is also similar to the results obtained by Tunc (2006), and Bar-On and Or-Bach (1988) where the students had insufficient knowledge and skills regarding the subject of sets. At the same time, it also supports the results of Way (1998) that the students had insufficient fore-knowledge and skills about the subjects of fractions, decimal fractions, fraction comparisons and percentages. This insufficiency observed in the foreknowledge about the subjects of numbers and sets prevented the students from internalizing the subject of probability (Bar-On \& Or-Bach, 1988; Jones et al., 1996; Sezgin-Memnun, Altun, \& Yilmaz, 2010) because while learning new pieces of information, students build these upon previous ones (Celik \& Gunes, 2007; Yagbasan \& Gulcicek, 2003). For this reason, it is important that students' foreknowledge about these subjects should be sufficient for learning about the subject of probability.

The eleventh-grade students in this study had difficulty in understanding the different probability problems addressed to them and in determining the appropriate strategies for the solutions. This result coincides with the result of the research carried out by Altun, Sezgin-Memnun, and Yazgan (2007) that the participants' inability and failures to solve the verbal problems were mostly associated with understanding the problem and making a plan for the solution steps of the problem-solving. Therefore, it is important and necessary that the students should use the problem-solving steps of comprehending and determining the resolution strategies in relation to the problem put forward by Polya (1985) and to develop their problem-solving skills in order to solve the probability problems. Besides, mathematical modeling could be used in probability learning especially in problems. Accordingly, studying and solving real-life probability problems helps students to develop different intuitions and to consider multiple representations (Gage, 2012).

Some participants did not know the limits of probability, and some were confused using concepts of probability, such as experiment, output, discrete event, dependent and independent events, and complementary event. Hence, students tend to create many misconceptions in terms of probability as well as in other subjects of mathematics. This indicates that students have difficulties in learning the basic concepts of probability. This result supports the conclusions of other studies (Batanero \& Serrano, 1999; Gurbuz, 2006; Sezgin-Memnun, Altun, \& Yilmaz, 2010) that probability is hardly perceived and understood by students. At the same time, it supports the results obtained in the studies conducted by Sezgin-Memnun, Altun, and Yilmaz (2010), and Tunc (2006) that students had difficulties in understanding the basic concepts of probability. However, students' incapability in some of these concepts may prevent them from understanding and using other concepts. For example, where students were unable to determine the concept of output completely may cause them not to be able to answer the occurrence or non-occurrence probability of an event. In this case, it becomes rather difficult for students to learn the subject of probability.

It is critical to enhancing the students' reasoning capabilities in solving probability problems because students generally use a trial-and-error method or prediction to solve probability problems. In this study, it was found that many eleven-grade students could not calculate all the possibilities and students could not think about all the conditions in the probability 
problems. This points to the difficulties of students in making reasoning about probability. This result is also consistent with the results of the researches conducted by Gurbuz (2006) and Sezgin-Memnun, Altun, and Yilmaz (2010).

Based on the observations and the obtained results, the following suggestions were introduced:

- There is a need to focus more on the learning of the basic concepts of probability when studying probability in mathematics lessons.

- In the learning of probability, students should not be made to memorize, and it is necessary to transfer the results obtained from sample space to students meaningfully by providing examples, which students can associate with real life.

- Attention should be paid to the use of tangible materials such as coins, dice, and geometrical shapes in the teaching process of probability in mathematics lessons.

- After students at middle school and high school remember necessary prior knowledge for solving probability problems and increase their readiness levels, the process of probability learning may start. The contribution of this matter to students' probability learning can be examined.

- When learning probability, students should have an idea of possible problems, which they are likely to encounter in probability, by solving different probability problem types and consolidate the basic concepts of probability.

\section{References}

Akdeniz, F. (2004). Olasilik ve istatistik. Adana, Turkey: Nobel.

Altun, M., Sezgin-Memnun, D., \& Yazgan, Y. (2007). Primary school teacher trainees's skills and opinions on solving non-routine mathematical problems. Elementary Education Online, 6, 127-143.

Bar-On, E., \& Or-Bach, R. (1988). Programming mathematics: A new approach in introducing probability to less able pupils. Journal of Mathematics Education in Science and Technology, 19(2), 281-297. https://doi.org/10.1080/0020739880190207

Batanero, C., \& Serrano, L. (1999). The meaning of randomness for secondary school students. Journal for Research in Mathematics Education, 30, 558-567. https://doi.org/ $10.2307 / 749774$

Durmus, S. (2004). Matematikte ogrenme gucluklarinin saptanmasi uzerine bir arastirma. Kastamonu University Education Journal, 12(1), 125-128.

Fischbein, E., \& Schnarch, D. (1997). The evolution with age of probabilistic intuitively based misconceptions. Journal for Research in Mathematics Education, 28(1), 96-105. https://doi.org/10.2307/749665

Gage, J. (2012). Towards a new probability curriculum for secondary schools. The 12th 
International Congress on Mathematics Education (ICME 12), $8^{\text {th }}-15^{\text {th }}$ July, Seoul.

Gurbuz, R. (2006). Olasılık kavramlarıyla ilgili geliştirilen öğretim materyallerinin öğrencilerin kavramsal gelişimine etkisi. Journal of the Buca Educational Sciences Faculty, $20,65-68$.

Gurbuz, R., Birgin, O., \& Catlioglu, H. (2012). Comparing the probability-related misconceptions of pupils at different education levels. Croatian Journal of Education, 14, 307-357.

Gurbuz, R., Toprak, Z., Yapici, H., \& Dogan, S. (2011). Ortaogretim matematik mufredatinda zor olarak algilanan konular ve bunlarin nedenleri. Gaziantep Universitesi Sosyal Bilimler Dergisi, 10(4), 1311-1323.

Jones, A. G., Thornton, C. A., Langrall, C. W., \& Mogill, T. A. (1996). Using children's probabilistic thinking to inform instruction. The $20^{\text {th }}$ Conference of the International Group for the Psychology of Mathematics Education, Proceedings Book, 3, 137-144.

Kazak, S. (2008). Ogrencilerin olasilik konularindaki kavram yanilgilari ve ogrenme zorluklari. In M. F. Ozmantar, E. Bingolbali, \& H. Akkoc (Eds.), Matematiksel Kavram Yanilgilari ve Cozum Onerileri (pp. 121-150). Ankara: Pegem Publications.

Kutluca, T., \& Baki, A. (2009). 10. sinif matematik dersinde zorlanilan konular hakkinda ogrencilerin, ogretmen adaylarinin ve ogretmenlerin goruslerinin incelenmesi. Kastamonu University Education Journal, 17(2), 609-624.

MEB (Ministry of Education). (2011). Ortaogretim Matematik (9, 10, 11 ve 12. Siniflar) Dersi Ogretim Programi. Ankara: MEB.

MEB (Ministry of Education). (2006). Ilkogretim Matematik (5, 6, 7 ve 8. Siniflar) Dersi Ogretim Programi. Ankara: MEB.

Munisamy, S., \& Doraisamy, L. (1998). Levels of understanding of probability concepts among secondary school pupils. International Journal of Mathematical Education in Science and Technology, 29(1). https://doi.org/10.1080/0020739980290104

National Council of Teachers of Mathematics. (2000). Principles and Standards for School Mathematics. Reston, VA: NCTM.

Papaieronymou, I. (2010). Recommended knowledge of probability for secondary mathematics teachers. The $6^{\text {th }}$ Congress of the European Society for Research in Mathematics Education, Proceedings Book, 358-367.

Polya, G. (1985). How to Solve It. New Jersey, NJ: Princeton University Press.

Sezgin-Memnun, D., Altun, M., \& Yilmaz, A. (2010). Elementary school eighth grade students' levels of comprehending basic concepts relating to probability. Journal of Uludag University Faculty of Education, 23(1), 1-29.

Shaughnessy, J. M. (1992). Research in probability and statistics: Reflections and directions. 
In D. A. Grouws (Ed.), Handbook of Research on Mathematics Teaching and Learning (pp. 465-494). New York, NY: Macmillan.

Tatar, E., Okur, M., \& Tuna, A. (2008). Ortaogretim matematiginde ogrenme gucluklerinin saptanmasina yonelik bir calisma. Kastamonu University Education Journal, 16(2), 507-516.

Topdemir, H. G. (2013). Bilimsel devrim yuzyıllarinda matematik. Bilim ve Teknik, 552, 88-89.

Tsakiridou, H., \& Vavyla, E. (2015). Probability concepts in primary school. American Journal of Educational Research, 3(4), 535-540. https://doi.org/10.12691/education-3-4-21

Tunc, E. (2006). Ozel ilkogretim okullari ile devlet okullarinin 8. sinif ogrencilerine olasilik konusundaki bilgi ve becerileri kazandirma düzeylerinin degerlendirilmesi (Unpublished Master's Thesis, Balikesir, Balikesir University).

Unlu, M., \& Aydintan, S. (2008). The effect of cooperative learning method on the student's success and recall levels of the 8th grade students learning in Permutation and Probability subject. Ahi Evran University Journal of Faculty of Education, 12, 1-16.

Walcott, H. F. (1994). Transforming Qualitative Data: Description, Analysis and Interpretation. Thousand Oaks, CA: Sage.

Way, J. (1998). Young Children's Probabilistic Thinking. The $5^{\text {th }}$ International Conference on Teaching Statistics (ICOTS 5), $21^{\text {th }}-26^{\text {th }}$ June, Singapore.

Yagbasan, R., \& Gulcicek, C. (2003). Misconceptions of science teacher candidates about work. Pamukkale University Journal of Education, 13, 110-128.

Yildirim, A., \& Simsek, H. (2005). Sosyal bilimlerde nitel arastirma yontemleri. Ankara: Seckin Publications.

\section{Copyright Disclaimer}

Copyright for this article is retained by the author(s), with first publication rights granted to the journal.

This is an open-access article distributed under the terms and conditions of the Creative Commons Attribution license (http://creativecommons.org/licenses/by/3.0/). 